Palavras chave:

Incêndios florestais

Prevenção e combate Impactos ambientais

Histórico:

Recebido 13/04/2012

Aceito 02/12/2013

Keywords:

Forest fires

Prevention and combating

Environmental impacts

Correspondência: allan.pereira@ifsuldeminas.edu.br

DOI:

| $0.1590 / 01047760201420031518$
Allan Arantes Pereira', Dalmo Arantes de Barros ${ }^{2}$, José Aldo Alves Pereira², Fausto Weimar Acerbi Júnior ${ }^{2}$, Fabiano Morelli ${ }^{3}$, José Roberto Soares Scolforo²

\section{FREQUÊNCIA ESPAÇO-TEMPORAL DOS FOCOS ATIVOS EM MINAS GERAIS DURANTE O PERÍODO DE 1999 A 2009}

RESUMO: Neste estudo, objetivou-se resgatar o histórico de focos ativos no estado de Minas Gerais, durante os anos de 1999 e 2009 para uma análise exploratória dos dados. Por meio de análise temporal, procedeu-se a uma análise dos meses e anos em que os focos foram mais frequentes, e do período crítico de ocorrência de focos ativos. Já, a análise espacial considerou a frequência e a densidade de focos ativos nos Núcleos do Instituto Estadual de Florestas (IEF). No caso das Unidades de conservação, analisou-se também a recorrência anual. No total, foram detectados 67.334 focos ativos em MG, no período de 1999 a 2009. A análise temporal revelou que o ano de 2003 apresentou o maior frequência, totalizando 10.929 focos, enquanto o ano de 2009 apresentou apenas 2.378 focos. O mês de maior frequência foi outubro com 24.149 focos registrados. As áreas com maior frequência, maior densidade e maior recorrência de focos ativos (neste último caso só em unidades de conservação), são consideradas mais críticas quanto aos focos ativos. Porém, a baixa frequência de focos e a alta densidade também são apontamentos de áreas críticas. Nas áreas de maior frequência de focos e baixa densidade, o tamanho da área influenciou diretamente na elevada ocorrência de focos ativos. Nessas áreas, sugerese uma análise de distribuição espacial para verificar se os focos ativos estão concentrados ou esparsos. O melhor cenário aqui apresentado é baixa frequência e densidade de focos ativos.

\section{SPACE-TIME FREQUENCY OF HOTSPOTS IN MINAS GERAIS FROM I999 TO 2009}

ABSTRACT: The aim of this study was to rescue the history of hotspots in the state of Minas Gerais during the years of 1999 to 2009 for an exploratory data analysis. Through temporal analysis, we proceeded an analysis of the months and years where foci have been more frequent and of the critical period of occurrence of hotspots. The analysis considered the spatial frequency and the density of hotspots in the State Forestry Institute (IEF) nuclei. In the case of conservation units, it was also analyzed the annual recurrence. In total, 67,334 hotspots were detected in MG during the period from 1999 to 2009. Temporal analysis revealed that the year 2003 had the highest frequency, totaling 10,929 hotspots; the year 2009, in turn, had only 2,378 spots. October was the month with the largest frequency, with 24,149 of hotspots recorded. Nuclei with higher frequency, higher density and higher recurrence of hotspots in the case of conservation units, present the worst scenario, being considered as the most critical hotspots. However, low frequency of hotspots and high density are also indicatives of critical areas. In areas of high frequency of hotspots and low density, the size of the area directly influenced the high incidence of active hotspots. In these areas it is suggested an analysis of spatial distribution to check if hotspots are concentrated or sparse. The best scenario presented here is low frequency and low density of hotspots.

' Instituto Federal de Educação, Ciência e Tecnologia do Sul de Minas Gerais - Poços de Caldas, Minas Gerais, Brasil 2 Universidade Federal de Lavras - Lavras, Minas Gerais, Brasil

${ }^{3}$ Instituto Nacional de Pesquisas Espaciais - Cachoeira Paulista, São Paulo, Brasil 


\section{INTRODUÇÃO}

A ocupação desordenada da região central do país para a expansão da produção agropecuária tem sido considerada a principal causa de degradação do Cerrado. Essa modificação na paisagem tem causado aumento na frequência de incêndios florestais, alterando a capacidade de recuperação dos elementos da biota (FIEDLER et al., 2006).

Os incêndios florestais também podem acelerar os processos de mudanças climáticas (WESTERLINGA et al., 20II) pela emissão de gases de efeito estufa na atmosfera. Os incêndios devem ser prevenidos por meio de uma gestão eficaz. No entanto, os fatores causais, por muitas vezes, são complexos (JIANG, 20II).

Nesse sentido, para estabelecer políticas de controle e prevenção, faz-se necessário conhecer o perfil dos incêndios. As estatísticas de ocorrência dos incêndios em vegetação são as principais ferramentas para se traçar esse perfil (CIPRIANI et al., 20I I; TORRES et al., 20I0).

Segundo Soares e Santos (2002), existe uma grande lacuna de dados estatísticos e registros sobre incêndios em áreas naturais. A falta de dados estatísticos e a dificuldade de registrar queimadas em lugares remotos faz dos focos ativos detectados por meio de técnicas de sensoriamento remoto, uma boa opção. Porém, deve-se atentar para o fato de não haver relação direta entre focos ativos e número de queimadas bem como áreas queimadas. Além disso, dependendo da resolução espacial, as queimadas menores não são captadas pelo sistema de monitoramento (PEREIRA et al., 20I2).

Os focos ativos, provenientes de processamentos digitais de imagens de satélites meteorológicos, que detectam a radiância emitida por objetos, cuja temperatura de brilho do pixel é, posteriormente, calculada através da Lei de Wien (JENSEN, 2009). Sendo assim, o satélite não é capaz de distinguir incêndios florestais (fogo em vegetação) de queimadas para fins agropecuários ou silvícolas. Tal distinção só pode ser feita por meio da interpretação de imagens de satélites de média a alta resolução espacial.

Desse modo, neste trabalho, objetivou-se resgatar o histórico de focos ativos no estado de Minas Gerais, durante o período de 1999 e 2009, bem como realizar uma análise exploratória desses dados.

\section{MATERIAL E MÉTODOS}

\section{Área de estudo}

A área de estudo abrange todo o território do estado de Minas Gerais, localizado na região sudeste do Brasil, com 853 municípios e uma população de, aproximadamente, 20 milhões de habitantes (INSTITUTO BRASILEIRO DE GEOGRAFIA E ESTATÍSTICA - IBGE, 20I0). Minas Gerais está inserido nos domínios fitogeográficos da Mata Atlântica, do Cerrado e da Caatinga (IBGE, 2004).

Duranteoperíodo de coleta dos dados, olnstituto Estadual de Florestas (IEF) foi o órgão responsável pela gestão das ações de prevenção e combate aos incêndios florestais, subordinado administrativamente à Secretaria de Meio Ambiente e Desenvolvimento Sustentável e dividido, hierarquicamente, em I 3 Regionais, compostas de 47 Núcleos e 244 Unidades de Conservação Estaduais (UCs), divididas em 59 UCs de Proteção Integral e 185 de Uso Sustentável.

\section{Base de dados}

A base de dados geográfica utilizada neste estudo, referente às divisões geopolíticas de Minas Gerais e da estrutura administrativa do IEF, foram adquiridas em formato shapefile junto ao laboratório de geoprocessamento e processamento digital de imagens do Departamento de Engenharia Florestal da Universidade Federal de Lavras.

Já, os dados de focos ativos são provenientes do satélite NOAA 12 e NOAA I5, os quais fazem parte da série de satélites polares do National Oceanic and Atmospheric Administration (NOAA). O sensor presente nessa série de satélites é o Advanced Very High Resolution Radiometer (AVHRR), que possui cinco canais, incluindo visível, infravermelho próximo, infravermelho médio e dois infravermelhos termais (SCHROEDER et al., 2008). A resolução espacial desses sensores no nadir é de I, $10 \mathrm{~km}^{2}$ e a revisita ao mesmo ponto ocorre a cada 12 horas (LIU, 2007). Neste trabalho, utilizou-se o NOAA 12 e 15 , em razão da disponibilidade da série histórica fornecida e, também, em razão de tais satélites terem sido utilizados como referência na detecção de focos ativos em diversos trabalhos científicos.

Os dados de focos ativos foram adquiridos na base de dado do INPE, em arquivo no formato shapefile, disponibilizados em http://www.dpi.inpe.br/proarco/ bdqueimadas, sendo realizado o download em 30/06/2010.

\section{Análises temporal e espacial}

A análise temporal dos focos ativos foi realizada por meio dos histogramas de frequência registrados ao longo de onze anos, com início em janeiro de 1999 e término em dezembro de 2009. 
Já, a análise espacial foi realizada por meio das áreas com contagem ou taxas agregadas, usualmente delimitadas por polígonos fechados. Essa análise consiste basicamente em contar a frequência de um evento pontual em um polígono previamente delimitado (CÂMARA et al., 2002). Este trabalho fundamentou-se na avaliação da contagem dos focos ativos nas Regionais do IEF, Núcleos do IEF, Unidades de Conservação do Estado de Minas Gerais e Municípios. Nas UCs foram analisadas também a recorrência anual de focos ativos. As análises das UCs, subdividiu-se em UCs de categorias de Uso Sustentável com UCs de Proteção Integral (BRASIL, 2000).

Calculou-se, também, a densidade de focos ativos a cada área de I.000 ha (RODRÍGUES; MENZONET, 2005).

\section{RESULTADOS E DISCUSSÃO}

\section{Análise temporal}

Ao total, foram registrados 67.334 focos ativos, perfazendo uma média anual de 6.121 ocorrências, sendo que 2003 foi o ano de maior registro, apresentando 10.929 e 2009 o ano de menor registro, com 2.378 focos ativos. $\mathrm{Na}$ Figura I, apresentam-se os dados de frequência de focos ativos por ano, durante o período de 1999 a $201 \mathrm{I}$.

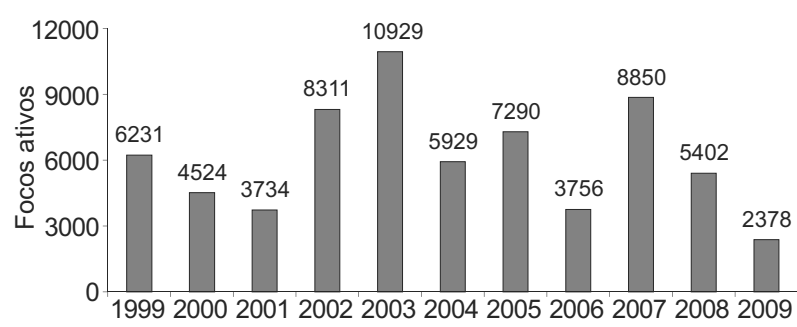

FIGURA I Frequência dos focos ativos em Minas Gerais (de 1999 a 2009).

FIGURE I Frequency of hotspots in Minas Gerais (from 1999 to 2009).

Com relação ao gráfico de frequência dos focos ativos detectados pela soma mensal durante os onze anos de análise, pode-se dizer, em linhas gerais, que 0 período crítico de presença de focos ativos em Minas Gerais inicia-se em julho e termina no mês de novembro, apresentando pico em outubro (Figura 2).

O uso do fogo é comum em regiões onde a agricultura é praticada com menor grau de tecnificação (LARA et al., 2007). Nos meses de setembro e outubro, são comuns queimadas em áreas rurais para a limpeza de pasto, limpeza de área com vistas ao plantio agrícola ou silvícola, limpeza para colheita ou eliminação de pragas

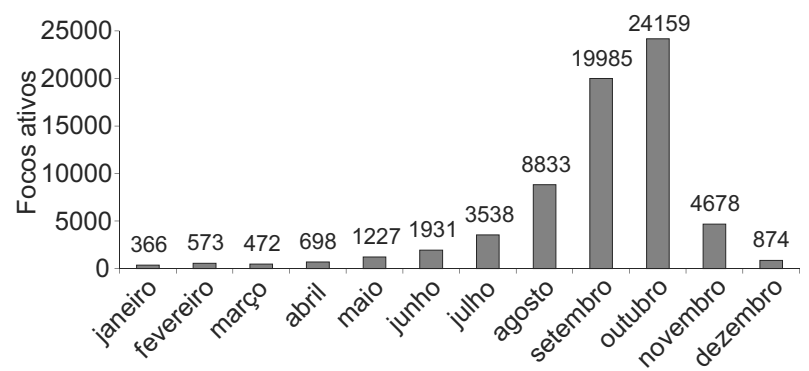

FIGURA 2 Frequência de focos ativos por mês em Minas Gerais (de 1999 a 2009).

FIGURE 2 Frequency of hotspots per month in Minas Gerais (from 1999 to 2009).

e plantas invasoras. Porém, essas práticas deterioram as características do solo e reduzem o potencial produtivo da vegetação nativa, devendo então serem evitadas (JAQUES, 2003). Além disso, práticas de manejo sem queima são consideradas práticas conservacionistas em termos de manutenção dos níveis de fertilidade do solo (HERINGER et al., 2002).

\section{Análise espacial}

\section{Frequência e densidade de focos ativos nas Regionais do IEF-MG}

No período de janeiro de 1999 a dezembro de 2009, foram detectados 67.334 focos ativos no estado de Minas Gerais, o que representa uma densidade de I, I focos a cada I.000 ha. Na Tabela I, apresentam-se os dados de frequência de focos ativos nas em cada Regional do IEF, bem como suas respectivas extensões territoriais, densidades dos focos ativos e a porcentagem de área com vegetação nativa.

As Regionais Norte, Nordeste, Alto Médio São Francisco, Noroeste e Alto Jequitinhonha, apresentaram uma alta frequência de focos ativos, superior à média das 13 Regionais (5.179 focos ativos). As mesmas Regionais tiveram alta densidade, sendo consideradas críticas quanto à frequência e densidade de focos ativos.

Tais regionais são caracterizadas por estarem em regiões de baixos índices de umidade (CARVALHO et al., 2008) e possuírem grandes áreas de vegetação nativa, com fitofisionomias dos Biomas Cerrado e Caatinga (CARVALHO; SCOLFORO, 2008).

A grande porcentagem de áreas com vegetação nativa e a alta frequência e densidade podem indicar que o fogo está sendo utilizado na conversão de áreas nativas em áreas agrícolas ou, então, para o manejo de pastagem em campos nativos. Outra hipótese é que o fogo utilizado por agricultores para a limpeza de área, sem as devidas 
TABELA I Frequência de focos ativos nas Regionais IEF entre 1999 a 2009, área de cada regional IEF, densidade de focos ativos em 1.000 ha e porcentagem de área com vegetação nativa das regionais IEF.

TABLE I Frequency of active hotspots in IEF Regionals between 1999 to 2009, area of each IEF Regional, density of hotspots in $\mathrm{I}, 000$ ha and percentage of native vegetation in the IEF Regionals.

\begin{tabular}{lcccc}
\hline Regionais do IEF & $\begin{array}{c}\text { Número de focos } \\
\text { ativos (NFA) }\end{array}$ & Área $\left(\mathrm{Km}^{2}\right)$ & $\begin{array}{c}\text { Número de Focos/ } \\
\text { Área (I.000 ha) }\end{array}$ & $\begin{array}{c}\text { Porcentagem de área } \\
\text { com vegetação nativa (\%) }\end{array}$ \\
\hline Regional Norte & 10.255 & 75.004 & 1,4 & 43,25 \\
Regional Nordeste & 10.242 & 54.931 & 1,9 & 34,57 \\
Regional Alto Médio São Francisco & 8.497 & 47.669 & 1,8 & 59,01 \\
Regional Noroeste & 7.103 & 58.063 & 1,2 & 39,65 \\
Regional Alto Jequitinhonha & 5.326 & 28.445 & 1,9 & 48,72 \\
Regional Rio Doce & 5.078 & 36.673 & 1,4 & 15,39 \\
Regional Triângulo & 4.908 & 53.786 & 0,9 & 14,45 \\
Regional Alto Paranaíba & 3.834 & 44.786 & 0,9 & 33,80 \\
Regional Sul & 2.859 & 52.669 & 0,5 & 18,38 \\
Regional Centro Oeste & 2.594 & 29.973 & 0,9 & 19,52 \\
Regional Centro Norte & 2.329 & 36.806 & 0,6 & 43,25 \\
Regional Centro Sul & 2.294 & 32.070 & 0,7 & 25,39 \\
Regional da Mata & 2.015 & 35.565 & 0,6 & 17,17 \\
\hline
\end{tabular}

Fonte dos dados da área das regionais e porcentagem de área de vegetação nativa. (CARVALHO; SCOLFORO, 2008).

precauções, saia do controle, e provoque incêndios na vegetação nativa. Segundo Soares (2004), uma das principais causas dos incêndios florestais no Brasil é a limpeza de área para fins agropecuários e florestais. A utilização das ferramentas de geoprocessamento, juntamente com outras práticas de aferição em campo, podem ser decisivas para corroborar as hipóteses inicialmente formuladas.

Dessa forma, o mapa de frequência (Figura 3) indica uma tendência de maior incidência de focos ativos apontada para as Regionais Alto Médio São Francisco, Norte, Nordeste, bem como as Regionais Noroeste, Alto Jequitinhonha e Rio Doce. Já, as áreas de menor incidência são as Regionais Centro Sul, Zona da Mata, Centro Norte, Centro Sul Centro Oeste, Sul, alto Paranaíba e triângulo.

A Regional Rio Doce, apesar de ter obtido baixa frequência de focos ativos quando comparada as outras Regionais, apresentou alta densidade de focos ativos. Segundo o Monitoramento da Flora nativa do Estado de Minas Gerais, essa Regional apresenta pouca vegetação nativa, correspondendo a $15,9 \%$ do seu território (CARVALHO; SCOLFORO, 2008). A alta densidade de focos ativos e as características da vegetação nativa podem indicar que o fogo é utilizado como prática frequente de manejo do solo. Bonfim et al. (2003), estudando agricultores do entorno de uma UC na Regional Rio Doce, constataram que o uso do fogo pelos agricultores dessa região tem fins agropecuários.

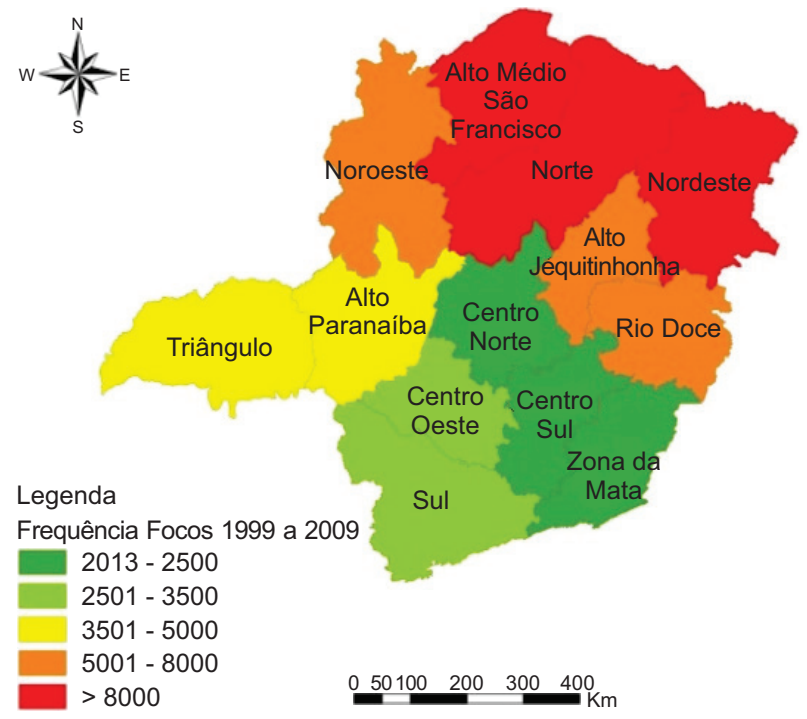

FIGURA 3 Mapa de frequência de focos ativos por Regionais do IEF em Minas Gerais.

FIGURE 3 Frequency map of hotspots per IEF Regional in Minas Gerais.

\section{Frequência de focos ativos nas Núcleos do IEF-MG}

O Núcleo com maior frequência de focos ativos nos últimos onze anos de avaliação foi o Centro Operacional Jaíba, seguido pelos Núcleos de Medina, Salinas, Jequitinhonha (Tabela 2).

A Figura 4 apresenta o mapa de frequência de focos ativos nas Núcleos do IEF. 
TABELA 2 Núcleos do IEF com maior frequência de focos ativos e respectivas informações sobre áreas, densidade de focos ativos, e porcentagem de área com vegetação nativa.

TABLE 2 Nuclei with the highest frequency of hotspots. Number of hotspots, Regional area in $\mathrm{km}^{2}$, density of active foci, percentage of the Regional area with native vegetation.

\begin{tabular}{|c|c|c|c|c|c|}
\hline Núcleos do IEF & Regionais & $\begin{array}{l}\text { Número de focos } \\
\text { ativos (NFA) }\end{array}$ & $\begin{array}{l}\text { Área } \\
\left(\mathrm{Km}^{2}\right)\end{array}$ & $\begin{array}{l}\text { Número de Focos/ } \\
\text { Área (I.000 ha) }\end{array}$ & $\begin{array}{l}\text { Porcentagem de } \\
\text { área com vegetação } \\
\text { nativa }(\%)\end{array}$ \\
\hline Centro operacional Jaíba & Alto Médio São Francisco & 4003 & 16455 & 2,4 & 57,99 \\
\hline Núcleo Medina & Nordeste & 3820 & 15667 & 2,4 & 51,96 \\
\hline Núcleo Salinas & Norte & 3287 & 16278 & 2,0 & 44,89 \\
\hline Núcleo Jequitinhonha & Alto Jequitinhonha & 2827 & 15430 & 1,8 & 37,59 \\
\hline Núcleo Itambacuri & Nordeste & 2637 & 14616 & $\mathrm{I}, 8$ & 28,94 \\
\hline Núcleo Arinos & Noroeste & 2492 & $|866|$ & $\mathrm{I}, 3$ & 48,63 \\
\hline Núcleo Janaúba & Norte & 2419 & 13393 & $\mathrm{I}, 8$ & 55,06 \\
\hline Centro operacional Januária & Alto Médio São Francisco & 2277 & 14777 & 1,5 & $58,32 *$ \\
\hline Núcleo Arcos & Centro oeste & 2178 & 18.348 & $\mathrm{I}, \mathrm{I}$ & 23,94 \\
\hline Núcleo Paracatu & Noroeste & 2108 & 13674 & I,5 & 30,66 \\
\hline
\end{tabular}

Fonte dos dados da área das regionais e porcentagem de área de vegetação nativa (CARVALHO; SCOLFORO, 2008$)$ * Em 2007 o Centro Operacional de Januária pertencia ao núcleo de São Francisco.

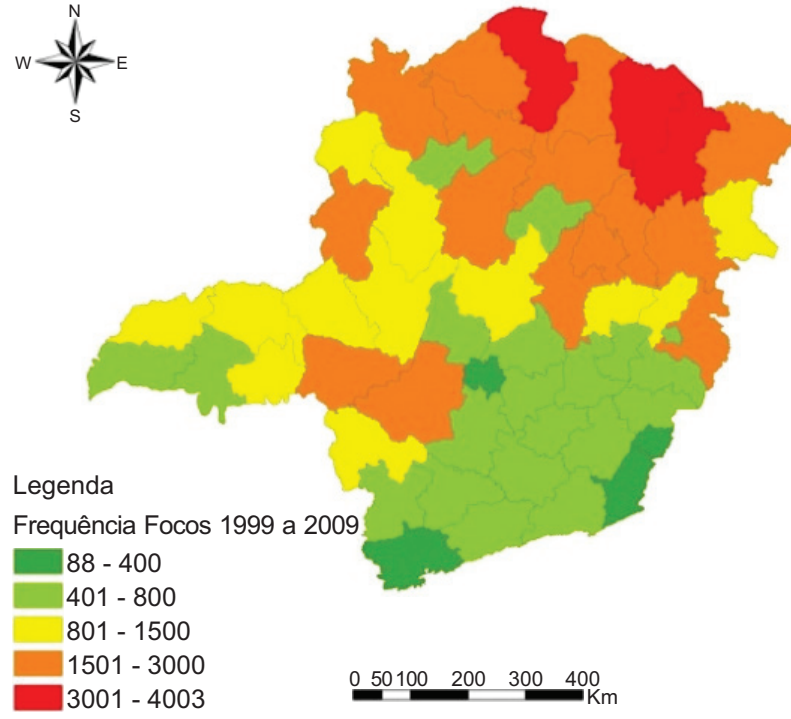

FIGURA 4 Mapa de frequência de focos ativos por Núcleos do IEF.

FIGURE 4 Frequency map of hotspots by IEF Nuclei.

Os Núcleos de Itamarandiba, Governador Valadares, Salinas, Jequitinhonha e Janaúba, apesar de não estarem entre aqueles com maior frequência, destacam-se pelas altas densidades de focos ativos, com respectivamente: 2,$45 ; 2, I ; 2,02$, I,8 e I,8 Focos/I.000 ha, respectivamente. Tais núcleos pertencem às Regionais apontadas como críticas quanto a focos ativos (Alto Jequitinhonha, Rio Doce, Nordeste, Norte), sendo o uso do fogo e as características da paisagem semelhantes ao descrito em suas regionais.

\section{Frequência de focos ativos nos municípios de Minas Gerais}

A análise da frequência de focos ativos por município mostrou que Paracatu, Januária, Unaí, Arinos e João Pinheiro foram os cinco municípios com maior ocorrência de focos ativos entre 1999 e 2009 (Tabela 3 e Figura 5).

Porém, quando analisada a densidade, verificase que os municípios Águas Vermelhas, Itamarandiba e Jaíba obtiveram maiores valores, enquanto João Pinheiro, Buritizeiro e Unaí, apesar de terem alta incidência de focos ativos, apresentaram menores valores de densidade de focos ativos. A análise da frequência por município diverge dos resultados de densidade de focos ativos, já que os municípios diferem em suas características intrínsecas, inclusive no seus tamanhos, mais que as Regionais e os Núcleos. Dos 853 municípios de Minas Gerais, 230 tiveram densidade de focos ativos acima da média de ocorrência estadual. $\mathrm{Na}$ Tabela 4, os dez municípios são apresentados com maior densidade de focos, bem como a frequência, área do município e porcentagem de vegetação nativa.

São João das Missões, apesar da baixa frequência quando comparado aos dez municípios com maior ocorrência, apresentou alta densidade de focos ativos. 
TABELA 3 Núcleo e regional a que pertence o município, frequência de focos ativos, área do município, densidade de focos em I.000 ha, e porcentagem de área com vegetação nativa dos dez municípios de maior frequência de focos ativos, em Minas Gerais, no período de 1999 a 2009.

TABLE 3 Nuclei and Regional to which belongs each municipality, frequency of hotspot, municipality area, foci density in I,000 ha and percentage of area with native vegetation of the ten municipalities with higher frequency of hotspots, in Minas Gerais, from 1999 to 2009.

\begin{tabular}{|c|c|c|c|c|c|c|}
\hline Município & Núcleo & Regional & $\begin{array}{l}\text { Número de } \\
\text { focos ativos } \\
\text { (NFA) }\end{array}$ & $\begin{array}{l}\text { Área } \\
\left(\mathrm{km}^{2}\right)\end{array}$ & $\begin{array}{l}\text { Densidade de } \\
\text { focos ativos } \\
\text { (NFA/l.000 ha) }\end{array}$ & $\begin{array}{c}\text { Porcentagem de } \\
\text { área com vegetação } \\
\text { nativa }(\%)\end{array}$ \\
\hline Paracatu & Paracatu & Regional Noroeste & 1463 & 8.229 & 1.8 & 33,19 \\
\hline Januária & São Francisco & $\begin{array}{c}\text { Regional Alto Médio São } \\
\text { Francisco }\end{array}$ & 1280 & 6.661 & 1.9 & 59,71 \\
\hline Unaí & Paracatu & Regional Noroeste & 1049 & 8.447 & 1.2 & 28,75 \\
\hline Arinos & Arinos & Regional Noroeste & 1018 & 5.279 & 1.9 & 59,00 \\
\hline João Pinheiro & João Pinheiro & Regional Noroeste & 914 & 10.727 & 0.9 & 40,94 \\
\hline Itamarandiba & Itamarandiba & Regional Alto Jequitinhonha & 756 & 2.735 & 2.8 & 56,38 \\
\hline Águas vermelhas & Medina & Regional Nordeste & 747 & 1.259 & 5.9 & 53,07 \\
\hline Buritizeiro & Jaíba & $\begin{array}{c}\text { Regional Alto Médio São } \\
\text { Francisco }\end{array}$ & 706 & 7.218 & 1.0 & 46,37 \\
\hline Jaíba & Pirapora & Regional Norte & 705 & 2.626 & 2.7 & 58,82 \\
\hline Grão Mogol & Bocaiúva & Regional Norte & 697 & 3.885 & 1.8 & - \\
\hline
\end{tabular}

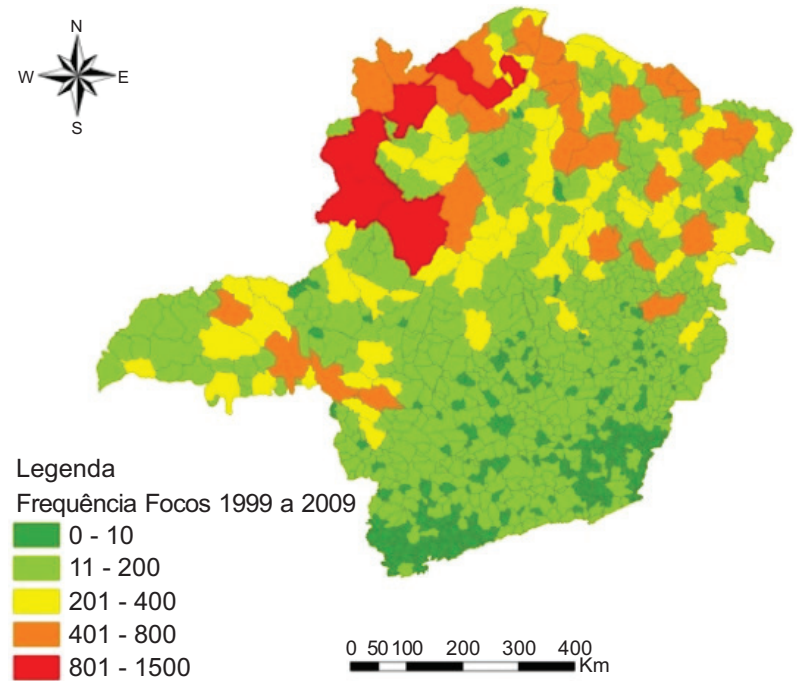

FIGURA 5 Mapa de frequência de focos ativos nos municípios de Minas Gerais.

FIGURE 5 Frequency map of hotspots in the municipalities of Minas Gerais.

Observa-se, também, conforme Tabela 4, que esse município tem alta porcentagem de vegetação nativa. Águas Vermelhas, Aricanduva, Ninheira, Felício dos Santos, Serra Azul de Minas, Francisco Badaró também são municípios com alta densidade de focos ativos, além de possuírem alta porcentagem de vegetação nativa.

Já, os municípios de Delta e Conquista se destacaram pela alta densidade de focos ativos e baixa porcentagem de vegetação nativa. $\bigcirc$ município de Periquito também apresentou alta densidade e baixa porcentagem de vegetação nativa. Do seu território, $9,86 \%$ é ocupado por reflorestamento (SCOLFORO et al., 2008), sendo que o fogo pode estar sendo utilizado para a limpeza dessas áreas. No entanto, é necessário um estudo mais detalhado para tal afirmação.

\section{Frequência e recorrência dos focos ativos nas Unidades de Conservação estaduais de Minas Gerais}

A análise dos focos ativos em UCs estaduais do território mineiro mostrou que, na categoria de Uso Sustentável (BRASIL, 2000), foram detectados I.74I focos ativos em I5 UCs no período de janeiro de 1999 a 2009, sendo mais frequentes as APAs Cochá e Gibão e a de Pandeiros. Na Tabela 5, caracteriza-se a frequência anual dos focos ativos nas nove UCs mais críticas.

As duas APAs com maior frequência de focos ativos estão localizadas na Regional Alto Médio São Francisco e possuem limites contíguos. Segundo o Zonemamento Ecológico Economico de Minas Gerais, essas áreas estão localizadas na zona de transição do índice de umidade entre as classes $\mathrm{Cl}$-Súbúmido Seco e D-Semiárido (CARVALHO et al., 2008). A vegetação de tais UCs é caracterizada pelo ecótone entre o Cerrado e a Caatinga, porém, com predominância de 
TABELA 4 Núcleo e regional a qual pertence o município, frequência de focos ativos, área do município, densidade de focos em 1.000 ha, e porcentagem de área com vegetação nativa dos dez municípios de maior densidade de focos ativos, em Minas Gerais, no período de 1999 a 2009

TABLE 4 Nuclei and Regional which belongs each municipality, frequency of hotspots, municipality area, hotspots density in I,000 ha and percentage of area with native vegetation of the ten municipalities with higher frequency of hotspots, in Minas Gerais, between 1999 to 2009.

\begin{tabular}{lcccccc}
\hline Município & Núcleo & Regional IEF & $\begin{array}{c}\text { Número de } \\
\text { focos ativos } \\
(\mathrm{NFA})\end{array}$ & $\begin{array}{c}\text { Área } \\
\left(\mathrm{km}^{2}\right)\end{array}$ & $\begin{array}{c}\text { Densidade de } \\
\text { focos ativos } \\
(\mathrm{NFA} / \mathrm{I} .000 \text { ha })\end{array}$ & $\begin{array}{c}\text { Porcentagem de } \\
\text { área com vegetação } \\
\text { nativa (\%) }\end{array}$ \\
\hline São João das Missões & Jaíba & Regional Alto Médio São & 435 & 680 & 6.4 & 70,85 \\
Águas Vermelhas & Medina & Regional Nordeste & 747 & 1257 & 5.9 & 53,07 \\
Aricanduva & Itamarandiba & Regional Alto Jequitinhonha & 139 & 244 & 5.7 & 45,57 \\
Ninheira & Salinas & Regional Norte & 563 & 1107 & 5.1 & 46,68 \\
Delta & Uberaba & Regional Triângulo & 48 & 102 & 4.7 & 2.03 \\
Conquista & Araxá & Regional Alto Paranaíba & 262 & 619 & 4.2 & 4.85 \\
Felício dos Santos & Itamarandiba & Regional Alto Jequitinhonha & 150 & 357 & 4.2 & 77,96 \\
Periquito & Timóteo & Regional Rio Doce & 94 & 228 & 4.1 & 15,67 \\
Serra Azul de Minas & Serro & Regional Alto Jequitinhonha & 89 & 219 & 4.1 & 36,9 \\
Francisco Badaró & Medina & Regional Nordeste & 172 & 459 & 3.7 & 44,95 \\
\hline
\end{tabular}

Fonte dos dados da área dos municípios e porcentagem de área de vegetação nativa (CARVALHO; SCOLFORO, 2008). * Em 2007 o Centro Operacional de Januária pertencia ao núcleo de São Francisco.

TABELA 5 Frequência anual dos focos ativos nas Unidades de Conservação de Uso Sustentável mais críticas em Minas Gerais (de 1999 a 2009).

Annual frequency of the hotspots in the most critical Conservation Units for Sustainable Use in Minas Gerais (from TABLE 51999 to 2009).

\begin{tabular}{|c|c|c|c|c|c|c|c|c|c|c|c|c|c|c|}
\hline \multirow{2}{*}{$\begin{array}{l}\text { Unidades de Conservação } \\
\text { de Uso Sustentável }\end{array}$} & \multicolumn{11}{|c|}{ Ano } & \multirow{2}{*}{ Total } & \multirow{2}{*}{$\begin{array}{l}\text { Area } \\
\mathrm{Km}^{2}\end{array}$} & \multirow{2}{*}{$\begin{array}{c}\text { Densidade } \\
\text { focos/ } \\
\text { I.000 ha }\end{array}$} \\
\hline & 1999 & 2000 & 2001 & 2002 & 2003 & 2004 & 2005 & 2006 & 2007 & 2008 & 2009 & & & \\
\hline APA Cochá e Gibão & 21 & 54 & 11 & 62 & 66 & 55 & 39 & 28 & 37 & 26 & 11 & 410 & 2846 & 1.4 \\
\hline APA Pandeiros & 18 & 37 & 18 & 56 & 57 & 41 & 22 & 16 & 26 & 22 & 13 & 326 & 3801 & 0.9 \\
\hline APA do Rio Uberaba & II & 5 & 9 & 29 & 20 & 34 & 14 & 36 & 46 & 17 & 30 & 251 & 528 & 4.8 \\
\hline APA Serra do Sabonetal & 6 & 12 & 7 & 16 & 31 & 31 & 9 & 6 & 21 & 9 & 2 & 150 & 865 & 1.7 \\
\hline APA Águas Vertentes & 30 & 11 & 3 & 21 & 10 & 14 & 16 & 3 & 25 & 7 & 2 & 142 & 762 & 1.9 \\
\hline REDES Veredas do Acari & 2 & 6 & 29 & 24 & 24 & 21 & 6 & 8 & 6 & 13 & 0 & 139 & 587 & 2.4 \\
\hline APA Sul RMBH & 15 & 5 & 5 & 18 & 28 & 1 & I & II & 36 & II & 0 & $|3|$ & 1632 & 0.8 \\
\hline APA Bacia do Rio Machado & II & 4 & 0 & 24 & 3 & 10 & 3 & 3 & 1 & I & 3 & 63 & 1265 & 0.5 \\
\hline APA Fernão Dias & 12 & 0 & 7 & 6 & 13 & 0 & 2 & 0 & 4 & 0 & 0 & 44 & |79| & 0.2 \\
\hline
\end{tabular}

APA: Áreas de Proteção Ambiental; REDES: Reserva Estadual de Desenvolvimento Sustentável.

Cerrado (INSTITUTO DE GEOCIÊNCIA APLICADA

- IGA, 2006). As fitofisionomias típicas desses biomas apresentam como características a alta inflamabilidade e, em áreas com predominância de lenhosas, sofrendo com o acúmulo de material combustível, o que propicia o alastramento do fogo em determinadas situações.

Já, quanto à densidade de focos ativos, a APA Cochá e Gibão obteve maior valor. A referida APA tem difícil acesso e baixa densidade demográfica. Além disso, sua distância do ponto central até o município mais próximo que é Januária é de $100 \mathrm{~km}$ em linha reta e até a APA Pandeiros é de $50 \mathrm{~km}$. As distâncias das cidades, as condições das estradas e a baixa densidade de ramais de acesso fazem com que aumente o tempo de combate das ocorrências dos incêndio. Essas duas UCs são caracterizadas por grandes latifúndios ocupados por pequenos posseiros que utilizam o fogo para o manejo do solo. No geral, o uso do fogo é feito sem as necessárias precauções e atingem áreas circundantes com vegetação nativa, provocando o incêndio florestal. 
Além da frequência e densidade, analisou-se a recorrência dos focos ativos. Essa informação é importante, uma vez que queimadas recorrentes afetam negativamente o estabelecimento de árvores e arbustos (HOFFMANN; MOREIRA, 2002). Na Figura 6, apresenta-se a recorrência de focos ativos durante os onze anos analisados.

A análise de recorrência de focos ativos nas unidades de Uso Sustentável mostrou incidência em todos os anos no período estudado, nas cinco unidades onde os focos foram mais frequentes: APA Cochá e Gibão, APA Pandeiros, APA do rio Uberaba, APA Serra do Sabonetal e APA das ÁGUAS Vertentes (Figura 7).
As UCs de uso sustentável com maiores frequências e densidades e recorrência, foram: a APA do Rio Uberaba; Reserva de Desenvolvimento Sustentável Veredas do Acari e; APA das Vertentes e Serra do Sabonetal.

$\mathrm{Na}$ categoria de Proteção Integral, na qual não é permitido o uso direto de recursos naturais (BRASIL, 2000), as UCs com maior quantidade de focos ativos entre 1999 a 2009 foram Parque Serra Nova e Parque Caminho das Gerais. Na Tabela 6, ilustra-se a frequência absoluta anual dos focos ativos nas dez UCs mais críticas.

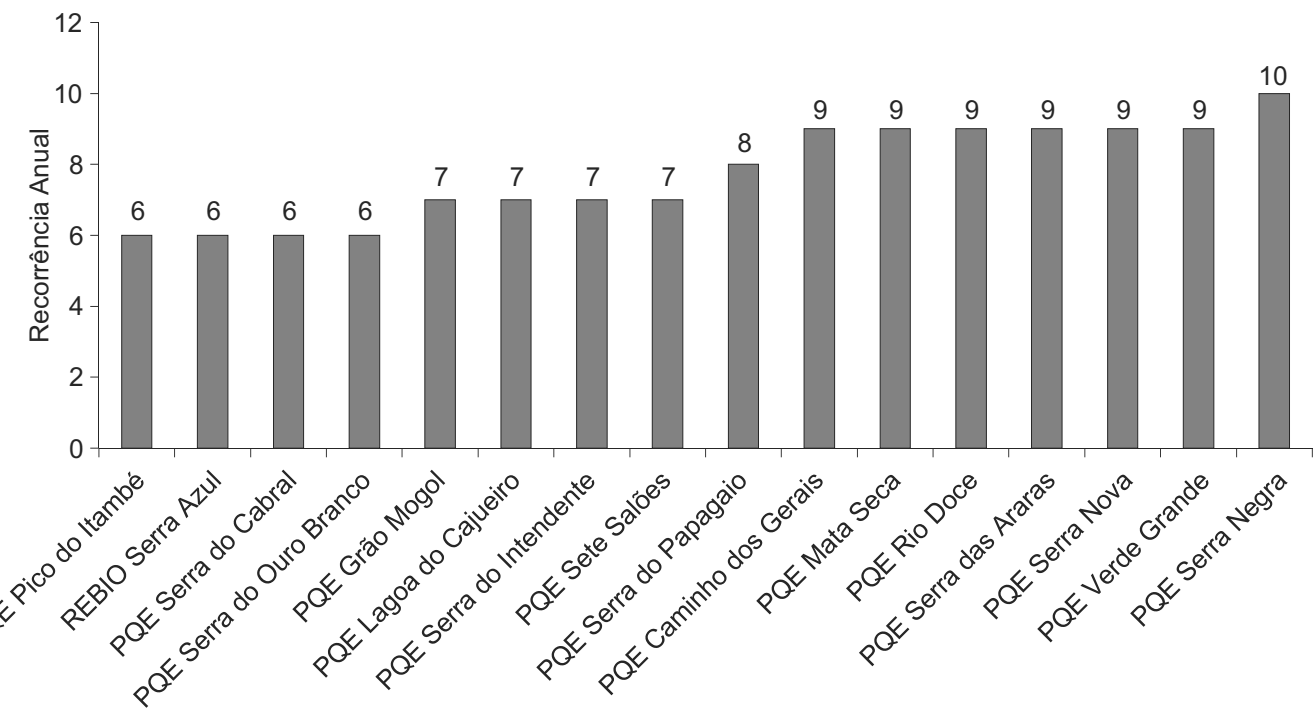

FIGURA 6 Recorrência anual de focos ativos durante os últimos I I anos (I999 a 2009) nas Unidades de Conservação de Proteção Integral em Minas Gerais.

FIGURE 6 Annual recurrence of hotspots over the past II years (1999 to 2009) in Conservation Units of Integral Protection in Minas Gerais.

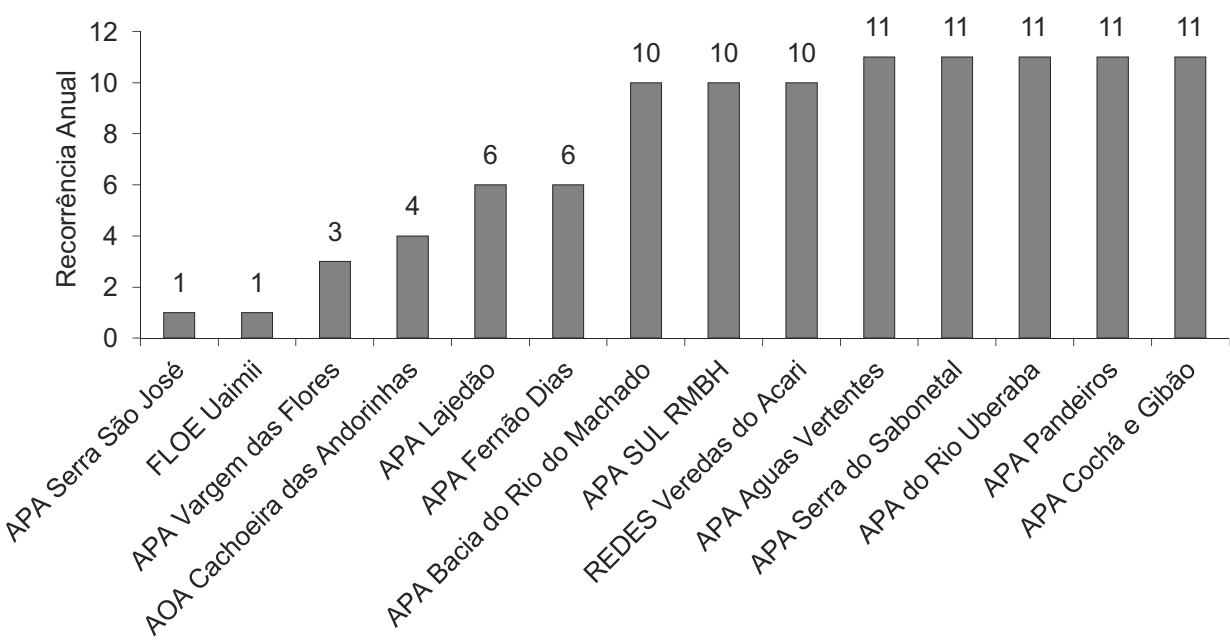

FIGURA 7 Recorrência anual de focos ativos nos últimos II anos (I 999 a 2009) nas Unidades de Conservação estaduais de Uso Sustentável em Minas Gerais.

FIGURE 7 Annual recurrence of hotspots over the past II years (1999-2009) in Conservation Units for Sustainable Use in Minas Gerais. 
TABELA 6 Frequência anual dos focos ativos nas dez Unidades de Conservação Estaduais de Proteção Integral mais críticas em Minas Gerais (de 1999 a 2009).

TABLE 6 Annual frequency of the hotspots in the ten most critical Conservation Units for Integral Protection in Minas Gerais (from 1999 to 2009).

\begin{tabular}{lcccccccccccccccc}
\hline $\begin{array}{l}\text { Unidades de Conservação } \\
\text { de Proteção Integral (PQE) }\end{array}$ & 1999 & 2000 & 2001 & 2002 & 2003 & 2004 & 2005 & 2006 & 2007 & 2008 & 2009 & & Total & $\begin{array}{c}\text { Área } \\
\mathrm{Km}^{2}\end{array}$ & $\begin{array}{c}\text { Densidade } \\
\text { Focos }\end{array}$ \\
\hline Serra Nova & 0 & 7 & 0 & 8 & 8 & 4 & 44 & 3 & 9 & 4 & 6 & 93 & 498 & 1,9 \\
Caminho das Gerais & 3 & 5 & 0 & 14 & 5 & 12 & 11 & 1 & 4 & 1 & 0 & 56 & 562 & 1,0 \\
Mata Seca & 3 & 1 & 0 & 9 & 1 & 2 & 12 & 2 & 18 & 1 & 0 & 49 & 153 & 3,2 \\
Lagoa do Cajueiro & 0 & 12 & 0 & 4 & 11 & 0 & 8 & 1 & 5 & 1 & 0 & 42 & 207 & 2,0 \\
Serra Negra & 3 & 0 & 3 & 3 & 8 & 4 & 6 & 8 & 1 & 5 & 1 & 42 & 125 & 3,4 \\
Grão Mogol & 0 & 0 & 0 & 1 & 3 & 1 & 8 & 0 & 6 & 18 & 1 & 38 & 327 & 1,2 \\
Verde Grande & 8 & 3 & 0 & 1 & 6 & 3 & 2 & 2 & 2 & 3 & 0 & 30 & 255 & 1,2 \\
Serra das Araras & 1 & 1 & 2 & 3 & 1 & 1 & 4 & 0 & 5 & 4 & 0 & 22 & 135 & 1,6 \\
Rio Doce & 6 & 2 & 2 & 1 & 2 & 0 & 3 & 2 & 1 & 2 & 0 & 21 & 359 & 0,6 \\
Sete Salões & 6 & 0 & 2 & 0 & 4 & 1 & 0 & 1 & 2 & 2 & 0 & 18 & 137 & 1,3 \\
\hline
\end{tabular}

PQE: Parques Estaduais.

As UCs de proteção integral - PQE Serra Negra, PQE Mata Seca, PQE Lagoa do Cajueiro e PQE Serra Nova - tiveram uma alta frequência e densidade, além da elevada recorrência de focos ativos. Lima et al. (2005) estudaram a efetiva proteção das UCs em Minas Gerais, e constataram que, em uma escala de 5 para o melhor cenário e decrescendo para I para o pior cenário, as UCs PQE Serra Negra, PQE Mata Seca e PQE Lagoa do Cajueiro tiveram nota I no que se refere ao controle de incêndios. Além disso, o estudo apontou que a efetividade de manejo nessas unidades foram consideradas insatisfatórias. Dessa forma, sugerese intensificar as atividades de prevenção em tais UCs.

\section{CONCLUSÕES}

Foram registrados 67.334 focos ativos no estado de Minas Gerais entre 1999 e 2009, perfazendo uma média anual de 6.121 ocorrências, representando uma densidade de I, I focos a cada $\mathrm{I} .000$ ha. O período com maior ocorrência de focos ativos foi de julho a novembro, apresentando pico em outubro

As Regionais Norte, Nordeste, apresentaram uma alta frequência e alta densidade de focos ativos. O Núcleo com maior frequência de focos ativos foi o Centro Operacional Jaíba, seguido pelos Núcleos de Medina, Salinas, Jequitinhonha.

Paracatu, Januária, Unaí, Arinos e João Pinheiro foram os municípios com maior ocorrência de focos ativos. Porém, quando analisada a densidade, os municípios Águas Vermelhas, Itamarandiba e Jaíba obtiveram maiores valores.

$\mathrm{Na}$ categoria de Uso Sustentável, foram detectados I.74I focos ativos em I5 UCs, sendo mais frequentes as APAs Cochá e Gibão e a de Pandeiros. Quanto à densidade de focos ativos, a APA Cochá e Gibão obteve maior valor entre as duas APAs. Porém, a APA do rio Uberaba e a Reserva de Desenvolvimento Sustentável Veredas do Acari foram as UCs de usos sustentável com maior densidade de focos ativos. A análise de recorrência de focos ativos mostrou incidência em todos os anos, nas cinco UCs onde os focos foram mais frequentes.

As UCs de proteção integral: PQE Serra Negra, PQE Mata Seca, PQE Lagoa do Cajueiro e PQE Serra Nova apresentaram alta frequência e densidade, além da elevada recorrência de focos ativos.

A análise exploratória dos focos ativos possibilitaram uma visão da frequência das queimadas nos anos e meses e, também, nas áreas analisadas, mostrando ser uma solução no resgate histórico de ocorrências e no apontamento de áreas mais críticas.

As análises realizadas por este trabalho são apenas uma primeira aproximação, sendo recomendada uma abordagem temporal e espacial com imagens de satélite de moderada a alta resolução espacial nas áreas consideradas mais críticas.

Sugere-se, ainda, uma investigação mais detalhada sobre a relação entre os dados temporais de focos ativos, dados meteorológicos e dados espaciais com manejo do uso do solo. 


\section{AGRADECIMENTOS}

Ao Instituto Estadual de Florestas (IEF) e à Universidade Federal de Lavras (UFLA) pelo apoio logístico, e ao CNPq pelo apoio financeiro durante o desenvolvimento deste trabalho, por meio de concessão da bolsa de apoio técnico.

\section{REFERÊNCIAS}

BONFIM, V. R.; RIBEIRO, A. G.; SILVA, E.; BRAGA, G. M. Diagnóstico do uso do fogo no entorno do Parque Estadual do Brigadeiro (PESB), MG. Revista Árvore, Viçosa, v. 27, n. I, p. 87-94, jan./fev. 2003.

BRASIL. Lei Federal $\mathbf{n}^{\circ} \mathbf{9 . 9 8 5}$, de 18 de julho de 2000. Institui o Sistema Nacional de Unidades de Conservação da Natureza - SNUC, estabelece critérios e normas para a criação, implantação e gestão das unidades de conservação. Brasília, 2000. Disponível em: <http://www.planalto.gov. br/ccivil_03/leis/19985.htm >. Acesso em: 8 set. 2013.

CÂMARA, G.; MONTEIRO, A. M.; DRUCKS, S.; CARVALHO, M. S. Introdução a ciência da geoinformação. São José dos Campos: INPE, 2002. 186 p.

CARVALHO, L. G.; OlIVEIRA, M. S. de; ALVES, M. C.; VIANELLO, R. L.; SEDIYANA, G. C.; DANTAS, A. A. A.; Clima. In: SCOLFORO, J. R. S.; CARVALHO, L. M. T.; OLIVEIRA, A. D. (Ed.). Zoneamento ecológicoeconômico de Minas Gerais: componente geofísico e biótico. Lavras: UFLA, 2008. p. 89-101.

CARVALHO, L. M. T.; LOUZADA, J. N. C.; SCOLFORO, J. R. S.; OLIVEIRA, A. D. Flora. In: SCOLFORO, J. R. S.; CARVALHO, L. M. T.; OLIVEIRA, A. D. (Ed.). Zoneamento ecológico-econômico de Minas Gerais: componente geofísico e biótico. Lavras: UFLA, 2008. p. I37-I50.

CARVALHO, L. M. T.; SCOLFORO, J. R. S. Inventario florestal de Minas Gerais: monitoramento da flora nativa 2005-2007. Lavras: UFLA, 2008. 357 p.

CIPRIANI, H. N.; PEREIRA, J. A. A.; SILVA, R. A.; FREITAS, S. G.; OLIVEIRA, L. T. Fire risk map for the Serra de São Domingos Park, Poços de Caldas, MG. Cerne, Lavras, v. I7, n. I, p. 77-83, jan./mar. 201 I.

FIEDLER, N. C.; MERLO, D. A.; MEDEIROS, M. B. Ocorrência de incêndios florestais no Parque Nacional da Capada dos Veadeiros, Goiás. Ciência Florestal, Santa Maria, v. 16, n. 2, p. |53-|6|, 2006.

HERINGER, I.; JACQUES, A. V. A.; BISSANI, C. A.; TEDESCO, M. Características de um Latossolo Vermelho sob pastagem natural sujeita à ação prolongada do fogo e de práticas alternativas de manejo. Ciência Rural, Santa Maria, v. 32 , p. 309-3|4, 2002.
HOFFMAN, W. A.; MOREIRA, A. G. The role of fire in population dynamics of woody plants. In: OLIVEIRA, P. S.; MARQUIS, R. J. (Ed.). The Cerrado of Brazil: ecology and natural history of a neotropical savanna. New York: Columbia University, 2002. p. 159-177.

INSTITUTO BRASILEIRO DE GEOGRAFIA E ESTATÍSTICA. Informações gerais. Rio de Janeiro, 2010. Disponível em: <http://www.ibge.gov.br/>. Acesso em: $6 \mathrm{dez}$. $20 \mathrm{ll}$.

INSTITUTO BRASILEIRO DE GEOGRAFIA E ESTATÍSTICA. Mapa de biomas e de vegetação. Rio de Janeiro, 2004. Disponível em: <http://mapas.ibge.gov.br/biomas2/viewer. html >. Acesso em: I5 jun. 2009.

INSTITUTO DE GEOCIÊNCIA APLICADA. Áreas de proteção ambiental no estado de Minas Gerais: demarcação e estudos para o pré-zoneamento ecológico. Belo Horizonte: APA Bacia do Rio Pandeiros, 2006. 27I p.

JACQUES, A. V. A. A queima das pastagens naturais: efeitos sobre o solo e a vegetação. Ciência Rural, Santa Maria, v. 33, p. |77-|8|, 2003.

JENSEN, J. R. Sensoriamento remoto do ambiente: uma perspectiva em recursos terrestres. São José dos Campos: Parêntese, 2009. 585 p.

JIANG, B. GIS-based multi-criteria analysis used in forest fire estimation: a case study of Northernmost Gävleborg county in Sweden. Gävle: Avdelningen för Industriell Utveckling, 20II. 38 p.

LARA, D. X.; FIEDLER, N. C.; MEDEIROS, M. B. Uso do fogo em propriedades rurais do Cerrado em Cavalcante, GO. Ciência Florestal, Santa Maria, v. I7, n. I, p. 9-I5, 2007.

LIMA, G.; RIBEIRO, G.; GONÇALVES, W. Avaliação da efetividade de manejo das unidades de conservação de proteção integral em Minas Gerais. Revista Árvore, Viçosa, v. 9, n. 4, p. 647-653, 2005.

LIU, W. T. H. Aplicações de sensoriamento remoto. Campo Grande: UNIDERP, 2007. 908 p.

PEREIRA, A. A.; PEREIRA, J. A. A.; MORELLI, F; BARROS, D. A.; ACERBI JÚNIOR, F. W.; SCOLFORO, J. R. S. Validação de focos de calor utilizados no monitoramento orbital de queimadas por meio de imagens TM. Cerne, Lavras, v. I8, n. 2, p. 335-343, abr./jun. 2012.

RODRIGUEZ, M. P. R.; MENZONET, Y. G. Definición de la época de incêndios forestales en un contexto multivariado. Floresta, Curitiba, v. 34, n. 2, p. I37-I43, 2005.

SCHROEDER, W.; PRINS, E.; GIGLIO, L.; CSISZAR, I.; SCHMIDT, C.; MORISETTE, J.; MORTON, D. Validation of GOES and MODIS active fire detection products using ASTER and ETM+ data. Remote Sensing of Environment, New York, v. II2, n. 5, p. 27II-2726, May 2008. 
SCOLFORO, J. R. S.; OLIVEIRA, A. D.; CARVALHO, L. M. T. Componente socioeconômico. In: Zoneamento ecológico-econômico de Minas Gerais: componente produtivo. Lavras: UFLA, 2008. p. 35-56.

SOARES, R. V. Incendiários: uma crescente causa de incêndios florestais. Revista da Madeira, Curitiba, v. 13, n. 78, p. |44-| 148, 2004.

SOARES, R. V.; SANTOS, J. F. Perfil dos incêndios florestais no Brasil de 1994 a 1997. Floresta, Curitiba, v. 32, n. 2, p. 219-225, 2002.
TORRES, F. T. P.; RIBEIRO, G. A.; MARTINS, S. V.; LIMA, G. $S$. Determinação do período mais propício às ocorrências de incêndios em vegetação na área urbana de Juiz de Fora, MG. Revista Árvore, Viçosa, v. 34, n. 2, p. 297303, 2010.

WESTERLINGA, A. L.; TURNERB, M. G.; SMITHWICKC, E. A. H.; WILLIAM, H.; ROMMED, W. H.; RYANE, M. G. Continued warming could transform Greater Yellowstone fire regimes by mid-2Ist century. PNAS, Washington, $v$. 108, n. 32, p. 13165-13170, Aug. 2011. 
